\title{
GLASBA IN NARODNA ZAVEST
}

\author{
STANE GRANDA \\ Znanstvenoraziskovalni center SAZU, Ljubljana
}

Izvleček: Slovensko narodno gibanje se je v osveščanju rojakov v veliki meri naslonilo na glasbo, zlasti zborovsko. Petje je navduševalo, pridobivalo, pa tudi brusilo ostrine različnih nasprotnikov. V času preganjanja Slovencev, zlasti pod fašizmom in nacizmom je bilo poglavitna oblika množičnega odpora. Glasba je mehčala tudi totalitarizem in prispevala $k$ demokratizaciji slovenske družbe.

Ključne besede: Slovenci, narodno gibanje, pevski zbori, narodno zatiranje, revolucija, demokratizacija
Abstract: In awakening compatriots to its cause, the Slovenian national movement has throughout recent centuries made much use of music, especially choral music. Singing spread enthusiasm and attracted participants, as well as lessening discord among various opposing groups. In times of persecution of the Slovenes, especially under Fascism and Nazism, it was the main form of mass resistance. Music also contributed towards the relaxation of totalitarianism and the democratization of Slovenian society.

Keywords: Slovenes, national movement, choral singing, national oppression, revolution, democratisation

»Veliko sem že slišal o lepoti kranjskega jezika. Zapojte mi eno pesem v njem!« Na približno tak način naj bi bil nagovoril dunajski dvorni pesnik Pietro A. Metastasio v cesarski prestolnici v začetku leta 1792 ljubljanskega »malega«, to je pomožnega škofa Janeza Antona de Riccija (1745-1818). Mož je bil sicer Italijan ali Furlan, ki je simpatiziral s slovenskim preporodom in je očitno znal tudi slovensko. Po zatrjevanju dr. Jakoba Zupana naj bi mu zapel neko pesem iz Linhartovega dela Ta veseli dan ali Matiček se ženi. Dvorni poet naj bi bil zadovoljen s pesmijo in naj bi bil nekoliko domišljavo izjavil, da jezik pesmi ni bil neprijeten njegovim ušesom. ${ }^{1}$

Gornji primer, ki so ga starejše generacije slovenskih izobražencev rade pripovedovale, nam najbolj zgovorno pove, kako so se mali in povrhu še »nezgodovinski« narodi lahko uveljavljali v kulturnem svetu. Njihov jezik je bil skorajda neprehodna ovira za drugače govoreče, slišan v petju pa je odpiral srca in vrata.

Če se še nekoliko zadržimo pri gornjem primeru, moramo ugotoviti, da omenjeni pesnik v nobenem primeru ni pričakoval nekega umetniškega dogodka, ampak zgolj jezik

1 Alfonz Gspan, Ricci Janez (Anton de), Slovenski biografski leksikon 3, Ljubljana, Slovenska akademija znanosti in umetnosti, 1960-1971, str. 97. Glej tudi Illyrisches Blatt, 5. marec 1831. 
v glasbi, njegove sposobnosti. V središču pozornosti je jezik, ne glasba. Kako pomembna je bila uglasbena slovenska govorica za njen prodor v kulturni svet, nam pove tudi znana ocena slovenskega jezika izpod peresa Jerneja Kopitarja: „Če je kateri jezik kdaj v nekem narečju kazal prikladnost za melodiko, potem to velja za kranjskega. Ta govor nima robatosti in sikanja, kakor ga imajo druga narečja, ker ga je italijanščina zelo omilila, sposoben je vsakega oblikovanja in dosega skoraj prijetnost italijanskih pesmi. «

Še bi lahko naštevali podobne primere, ki jih radi povlečemo iz rokava predvsem takrat, ko se razburjamo nad izvedbami nekaterih oper v ljubljanski operi v originalnem jeziku. Zanimivo je, da se pri drugih glasbenih oblikah taki spori ne pojavljajo. Opera je bila vendar namenjena najširšim ljudskim masam in njena fabulativnost ima tolikšen pomen, da jezika petja ni mogoče ignorirati. Instrumentalni in besedni del neke glasbene umetnine je nedvomno umetniška celota, vendar se je treba zavedati pomena in sporočilnosti tekstovnega dela, sicer ga ne bi bilo, pa tudi sicer bi bil verjetno instrumentalni del drugačen. Slednje je treba poudariti, ker tudi v nadaljevanju ne bomo govorili o glasbi kot taki, ampak o glasbi, ki je podrejena besedilu. Ta podrejenost je različna. Njen muzikalni del mora biti tak, da pritegne, da ga je prijetno slišati tudi tistemu, ki besedila ne razume, da ga je prijetno slišati tudi od daleč, toda pomen besedila je najmanj enakovreden.

Uvodoma moramo razčistiti še z vlogo čiste instrumentalne glasbe v narodnoprebudnem smislu. Ni res, da tudi povsem instrumentalna glasba ni imela takega namena. To posebno velja za primere, ko je bila povezana z ljudsko ali bolje narodno glasbo. Ta lahko prihaja do izraza zaradi svoje melodičnosti ali pa nepetega besedila kot tudi izbora instrumentov oziroma zasedbe. Instrumentalna glasba, pa naj bo solistična, majhni sestavi ali pa kar orkestri ali godbe, je lahko dokaz, kaj zmore naš narod, kakšne umetnike in talente ima ali pa z zasedbo poudarjamo njihovo narodno barvo. Vrh tovrstnih, predvsem antigermanskih pa tudi proslovanskih ali projugoslovanskih prizadevanj oziroma političnih nazorov pomenijo tamburaški orkestri. Ob tem si dovoljujem še neko provokacijo, ki z moje strani ni mišljena tako, vendar jo bodo gotovo mnogi od vas tako razumeli. Gre za poskus narodnoprebudne ocene tako imenovane slovenske narodnozabavne glasbe. Zavedam se njenega glasbenega sorodstva z neslovenskimi narodi jugovzhodnega alpskega prostora, vendar je bilo in je v njej še vedno toliko slovenskega, da je praktično noben sosedni narod ne zna tako dobro posnemati, da je ne bi bilo mogoče prepoznati kot slovensko. Mogoče je v teh primerih njen umetniški del, mojstrstvo na instrumentih puščamo ob strani, najbolj podrejen zabavnemu, $v$ tem primeru ideološkemu, toda ravno tega pri tej vrsti glasbe ne gre zanikati.

Nobena skrivnost ni, da sta tako stara kot socialistična Jugoslavija hoteli ustvariti jugoslovanski narod, le da druga z delavskim oziroma proletarskim predznakom. V ta politična prizadevanja so vključevali tudi različne umetnosti. Slovenski odgovor je bil vselej, kljub oportunizmu nekaterih okolij in posameznikov, intenziviranje slovenske kulture. Spomnimo se samo, koliko kulturnih domov je v času stare Jugoslavije po uvedbi diktature 1929. leta nastalo na podeželju! V njih je bila slovenska peta in govorjena beseda glavna vsebina. V novi Jugoslaviji je bila kultura kot vse družbeno in javno življenje vodena, v funkciji ideološke preobrazbe družbe, zato je lahko tudi zaspala, na kar še

\footnotetext{
2 Nav. delo, str. 64-65.
} 
danes ponekod kažejo propadajoči zadružni domovi. Prav po njihovem ugašanju pa se je začela razvijati narodnozabavna glasba, ki so se je oprijele najširše slovenske množice doma in v zamejstvu. Oblast nad njo ni bila navdušena, vendar ji ni mogla očitati nič ideološkega. V poskusih jugoslovanizacije slovenske družbe, ki smo jo posebno čutili v JLA, je postajala vse bolj identifikacijski simbol Slovencev. Postala je naše vezivo s srednjo Evropo in naše ločilo od toliko opevanega bratstva in enotnosti. Bodimo pošteni in priznajmo, da Slovenci nismo po ničemer toliko prepoznavni v Evropi kot po ansamblu bratov Avsenikov. Med ansambli, ki so jih posnemali, je bilo vse mogoče, toda prav oni kot vodilni ali bolje vzorčni so ohranili svojo nacionalno samobitnost, četudi so nekatere vokalne skladbe izvajali v nemškem jeziku. Leta 1990 so povsem nedvoumno pokazali tudi svojo politično demokratično opredelitev. Da je temu tako, dokazuje tudi obračun z njo, ki ga izvajajo pristaši multietičnosti slovenske kulture, pristaši anacionalne pop kulture, ki so jo razglasili za tako imenovano »govejo glasbo« in jo na vse načine, predvsem pa s smešenjem, izrivajo iz javnega življenja. Pogosto njeno izvajanje označujejo kot manifestacijo slovenskega primitivnega podalpskega nacionalizma. Nadaljnje, predvsem pa poglobljene analize tega vprašanja ne bom nadaljeval, ker bi nas preveč oddaljilo od osnovne teme. Veljalo pa bi v tem kontekstu o njem nadaljnje razpravljati, pri čemer pa mi ni povsem jasno, ali je muzikološka družba za to primerna sredina.

Začetke narodnoprebudne glasbe gre mogoče iskati že v protiturških vojnah, gotovo pa je dokaj jasna kontinuiteta $\mathrm{z}$ brambovsko glasbo iz časov bojev proti Francozom. Seveda temeljni namen teh pesmi ni bil budenje slovenske narodne zavesti, vendar je to povzročilo že tiskanje slovenskih besedil kakor tudi nekatera besedila sama, ki z uporabo besede Slovenec presegajo tedanjo razdeljenost na dežele.

Naslednji, povsem zavestni korak predstavlja delovanje Antona Martina Slomška v celovškem semenišču. Kot je znano je leta 1821 kot semeniščnik v njem ustanovil slovenski zbor. Na vsakoletnih otvoritvenih govorih je govoril predvsem o narodnem vprašanju na način, v katerem je že mogoče povsem realno videti idejo združene Slovenije. Iz njegovih ust je bilo slišati, da je Slovenec Kranjec, Korošec, Štajerec, zahteval je »eno hišo, eden rod, eno slovenstvo«, kar je, povedano s kasnejšimi besedami, Združena Slovenija. Za potrebe zboraje pisal tudi pesmi. Med njimi ima ena naslov Slovenstvo, druga Slovenski raj. Bil je prvi, ki je zavestno vključil slovensko zborovsko glasbo v narodnoprebudna in narodnobrambna prizadevanja, kar so potem še mnogi posnemali. Da je dejansko razumel pomen glasbe tudi v tem smislu, je pokazal ob preselitvi sedeža škofije iz Št. Andraža na Koroškem v Maribor, ko je svojega stolnega organista »posodil« mariborski čitalnici.

V nekem smislu prelomno je v tem kontekstu tudi revolucionarno leto 1848/49. Kot je znano, je ljubljansko Slovensko društvo, ki je bilo povsem nedvoumno politično, začelo izdajati Slovensko gerlico, v kateri so bile vokalne skladbe. Idejo za to publikacijo, ki je do 1862. leta izšla v sedmih zvezkih, gre iskati v odmevih na znani dunajski pevski nastop Ljubljančana Legata, ki je tam izvajal eno prvih koncertno zapetih slovenskih pesmi. V poročilu o temu koncertu je dr. Janez Bleiweis, ki je vodil ljubljansko Slovensko društvo, zapisal: »Gospod Ž - r, ki so nam to novico oznanili, prav zlo obžalujejo, de se dosihmal še noben Krajnc ni dela lotil, kranjskih pesem z napevi (vižami) vred na svitlo dati. « $\ll^{3}$ Ali

3 Novice, 18. novembra 1846. 
je mogoče datum izdaje tega poročila šteti za začetek pobude za izdajo slovenskih zborovskih pesmi v notni obliki, prepuščam strokovnjakom.

Nekoliko manj je znano, da je imela lasten pevski zbor tudi graška Slovenija. To je bilo ljubljanskemu sorodno društvo, vendar neprimerno starejše, predvsem pa veliko bolj organizirano in politično naravnano. Zbor je vodil Gustav Ipavec, ${ }^{4}$ sodeloval pa je tudi Benjamin Ipavec.

Glasba je bila sestavni del tudi nekaterih narodnih manifestacij po drugih slovenskih mestih, na primer v Novem mestu in še kje, vendar vsebinske podrobnosti niso znane.

Desetletje po revoluciji velja za obdobje Bachovega absolutizma ali neoabsolutizma. Predvsem na podlagi Trdinovega pisanja je v slovenski zavesti občutek, da je to čas hudega preganjanja slovenskega jezika in slovenske kulture. Gotovo pristašem revolucije ni bilo lahko, toda izdajanje Novic, nastanek Mohorjeve družbe kot prve vseslovenske organizacije, izdajanje slovenskih šolskih knjig za vse Slovence in nenazadnje tudi izdaja kar 7 zvezkov zgoraj imenovane Slovenske gerlice do leta 1862 govorijo o potrebi po reviziji tega političnega obdobja.

Obdobje čitalnic, ki je povezano z nastankom ustavne dobe, je za sodobno muzikologijo gotovo veliko bolj pomembno. To je čas prireditev v manjših prostorih, gostilniških sobah, kazinskih prostorih pa tudi zasebnih salonih, ki pa jih je bilo malo. To ni bil čas velikih manifestativnih nastopov, ampak čas mobilizacije slovenskih meščanskih krogov ali bolje uglednejših posameznikov in posameznic, ko je bilo treba uvajati slovenski jezik v javnost, dokazovati na vseh področjih njegove zmožnosti, hkrati pa tudi dokazovati, kakšne talente imamo med seboj Slovenci. Treba je bilo prebiti miselnost, da so Slovenci predvsem kmetje. V nekem smislu je šlo za nadaljevanje Prešernovega kulturnega koncepta, ki je skušal slovensko kulturo oblikovati od zgoraj navzdol.

V zgodovinopisju je pogosto zaslediti omalovaževanje čitalniških prireditev. Njihovi kritiki imajo sicer načelno prav, vendar ne razumejo, da te niso bile prvenstveno umetniške prireditve, ampak kulturnopolitične. Ponavlja se podobna napaka kot pri ocenjevanju Bleiweisovih Novic, ki so bile kmetijske in obrtne, se pravi gospodarske, njihov urednik pa ni bil njihov lastnik, saj jih je izdajala Kranjska kmetijska družba. Kljub temu pa je treba poudariti, da je iz čitalniškega kroga izšlo kar nekaj resničnih glasbenih umetnikov, kjer bi na prvem mestu izpostavili opernega pevca Josipa Nollija (1841-1902). Iz teh umetniških ambicij čitalniškega gibanja je dejansko izšla tudi Glasbene matica, konkurent za nemško označeno Filharmonično družbo, ki pa je hotela združevati narodnoprebudno glasbeno delovanje $\mathrm{z}$ umetnostjo in je v tem tudi v veliki meri uspela. Spomnimo se samo njenega zbora, glasbenikov, ki so z njo sodelovali, njene publicistične in vzgojne dejavnosti, podružnic, zlasti tržaške, in nenazadnje tudi ustanovitve konzervatorija 1919. leta.

O vlogi glasbe na taborskih shodih ${ }^{5}$ v letih 1868-1871 nimamo neposrednih glasbenih programov, vendar brez petja kot mobilizatorja narodnih čustev ni šlo. Petje je bilo tu tudi v svoji povsem družabni funkciji. V tem času je bila tako kot na drugih področjih pomembna pomoč »čeških bratov«. Zanimivo je, da je bila takratnim Slovencem njihova

4 Igor Grdina, Ipavci. Zgodovina slovenske meščanske dinastije, Ljubljana, Založba ZRC, ZRC SAZU, 2001, str. 111.

5 Taborsko gibanje na Slovenskem. 
glasba veliko bližja kot pa južnoslovanska, kar posredno kaže na kulturno sorodnost. Kljub takratnemu in kasnejšemu jugoslovanstvu južnoslovanska glasba med širokimi ljudskimi množicami ni našla posnemovalcev.

V tem času, zlasti pa v naslednjih desetletjih so za glasbeno spremljavo javnih slovenskih političnih prireditev njihovi organizatorji enostavno angažirali dele vojaških godb, ki so se, ne glede na politiko, rade odzivale takim vabilom. Očitno tudi niso bile drage. Nastajale in razvijale so se tudi domače godbe, pri čemer so bili aktivni številni češki prišleki. Razmah strankarskega življenja je v devedesetih letih 19. stoletja sprožil vsesplošno tekmovalnost tudi na kulturnem področju. To se je odražalo v številnih novih kulturnih društvih, ki so običajno imela dve sekciji: dramsko in glasbeno.

Glede pomena glasbe v narodnoprebudnem delovanju je posebno ilustrativen primer Prekmurja. Čeprav so bili skoraj tisočletje ločeni od ostalih Slovencev, so obdržali tako svoj jezik kot petje. Za razliko od večinskih Madžarov, ki pojejo enoglasno, so ostali pri večglasju in v njem videli celo svojo večvrednost.

Izjemen pomen pa je dobila zborovska glasba po I. svetovni vojni, zlasti pri Slovencih onkraj Karavank in rapalske meje. ${ }^{6}$ Bila je na eni strani izraz samonikle slovenske kulture, slovenskega jezika, slovenskih organizacijskih sposobnosti, skratka slovenstva kot celote. Nastajali so številni zbori, narodnoprebudni duh se je širil tudi v cerkev. Zaradi slovenskega petja so bile tudi človeške žrtve. Še nedavno je vsak pošten Slovenec poznal primer nesrečnega Lojzeta Bratuža iz Podgore pri Gorici, ki pa ni bil edini. Miha Habih, koroški pevodja, ki je bil zaradi slovenskega petja tudi ubit, je premalo znan. Poleg prepevanja doma pa so, zlasti koroški Slovenci, združili svoje pevske sile, se odpravili na pot v jugoslovanski del Slovenije in skušali pridobiti slovensko in jugoslovansko javnost. Vzbudili so globoka čustva, žal pa niso premaknili politikov. Znano je tudi, da so s pomočjo pevcev po atentatu na kralja Aleksandra Slovenci skušali pridobiti Francoze. Nasploh velja na tem mestu ugotoviti, da je glasba, zlasti zborovsko petje, silno uspešno orožje za mobilizacijo ljudskih množic, manj uspeha pa je pri politikih, ki so hladni računarji, predvsem pa nečustveni ljudje.

Mnogim je še v spominu jesenski koncert akademskega pevskega zbora 1941. leta v Ljubljani, že pod italijansko okupacijo, ki je imel jasno politično vsebino.

Pomen glasbe se je še intenziviral med II. svetovno vojno. Znano je, da sta slovenska nasprotna tabora tekmovala ali bolje se bojevala tudi na glasbenem področju. Da tu ni šlo le za tekmovanje, ampak za dejanski boj, pove dovolj tudi fizična likvidacija domobranske godbe na enem množičnih povojnih morišč. ${ }^{7}$ Če so imeli domobranci boljšo godbo in mogoče tudi zbor, pa se le zdi, da je bila partizanska pesem za ušesa bolj privlačna, manj izumetničena. Tako je bilo že tudi medvojno mnenje nekaterih domobrancev.

Pevske zbore so imeli tudi interniranci. Znan je pevski zbor iz Dachaua, ki je bil sicer eden številnejših v tem taborišču, vendar menda med najboljšimi. Tako je vsaj pred

6 Spominska pričevanja so izredno številna. Primerjaj Borut Rutar, TIGR proti duhovnemu genocidu fašizma nad Primorci. Tolminsko 1918-1941, Ljubljana, Tangram. Društvo za preučevanje zgodovine, literature in antropologije, 1996.

7 Eden izmed redkih, ki je ušel nesrečni usodi, je bil skladatelj Primož Ramovž, ki je igral na krilni rog. 
leti zatrjeval v radijskem intervjuju njegov član Božo Grošelj, kasneje tenorist Slovenskega okteta. ${ }^{8}$ Svoj zbor so imeli tudi interniranci v Gonarsu, vodil ga je Samo Hubad, katerega naloga je bila tudi prikrivanje znamenitega bega iz tega taborišča s petjem. Zbor so imeli tudi slovenski prekomorci. Zanimiv je podatek, da so slovensko pogosto zapeli tudi slovenski mobiliziranci v nemško vojsko. Ne kot zbor, toda petje je bilo slovensko.

Izjemen propagandni pomen je dobilo zborovsko petje tudi po II. svetovni vojni. Izpostavil bi Pevski zbor Srečko Kosovel in podobne ansamble, ki so bili angažirani tudi za krojenje slovenske zahodne meje. Podobne naloge so imeli tudi pevci s Koroške. Oblast jih je skušala mobilizirati celo za utrjevanje tako imenovane neuvrščene politike. Pevski zbor Vinko Vodopivec je poslala celo v Egipt.

Doslej smo opozarjali predvsem na zborovsko glasbo kot sredstvo navduševanja za narod, za pridobivanje podpore pri tujcih, veljalo pa bi samo opozoriti tudi na glasbo kot sredstvo za demokratizacijo in strpnost v družbi. Večini je verjetno znano, da nekatere pesmi ni bilo zaželeno peti ne glede na njihovo umetniško vrednost. Nekaterim so z ideološkega vidika »čistili« besedila. Določene pesmi, ki so bila preveč blizu verskim pogledom ali besedilom, so enostavno izrinili iz družbe. Mnogi ljudje so v času enoumja $\mathrm{v}$ večernih in nočnih urah v božičnih in velikonočnih dnevih iskali tuje radijske programe z ustrezno glasbo. Seveda pa so bila tudi nasprotna prizadevanja. V spominu imam sporočilo, da je bil pevski zbor Vinko Vodopivec pod vodstvom Antona Nanuta prvi, ki je po II. svetovni vojni začel na javnih koncertih prepevati Gallusa. Te vesti nisem uspel preveriti, veljalo pa bi glasbeno preteklost presojati tudi v smeri, ki sem jo zgolj nakazal. ${ }^{9}$

Zanimivo je dejstvo, da so tudi v petnajstdnevni vojni za slovensko osamosvojitev 1991. leta slovenski vojaki že formirali pevske skupine.

Slovenci v zvezi s svojim narodnoprebudnim delovanjem poudarjamo predvsem pomen govorjene in pisane slovenske besede. Že bežen sprehod skozi zgodovino pa pokaže, da je imela glasba, peta ali instrumentalna, podobno vlogo. Izjemno delo sta petje in tudi igranje na različne instrumente opravila v 19. stoletju, ko sta premagovala tudi nekatere jezikovne ovire. Glasba se je pokazala kot odlično sredstvo ne le pri mehčanju nasprotnikov, ampak tudi pri pridobivanju mlačnih in indiferentnih. V primerih, ko je bil slovenski jezik prepovedan, na primer v času fašizma, pa je petje pogosto ostalo edino »nacionalno« orožje, saj besedilo pogosto podleže melodiji ali pa jo ta prekrije. Nasploh je muziciranje tudi težje cenzurirati, saj mu je težje očitati subverzivnost. Iz naše polpretekle zgodovine vemo, da so imeli totalitarni režimi tudi na tem področju strokovnjake, in to običajno iz glasbenih vrst. Na drugi strani pa je bila glasbena govorica tudi $v$ funkciji najširše samoobrambe, kar so Slovenci s pridom izkoriščali v novejših zgodovinskih obdobjih. Žal je podrobnosti običajno težko ugotavljati, saj podatki govorijo le o glasbenem programu, ne pa podrobnostih in celo izvajalcih.

Izjemen pomen ima glasba tudi pri slovenskih izseljencih, saj je pogosto še edino sredstvo narodne samoidentifikacije. Sprva jim je pomenila vez z domačim okoljem, bila

\footnotetext{
8 Pogovor je ohranjen v arhivu RTVS.

9 Nemalo takih podatkov sem slišal od nekdanjih sopevcev Akademskega pevskega zbora Vinko Vodopivec.
} 
je sredstvo ohranjanja narodne zavesti, skupnosti, sedaj je pogosto pomembna pri iskanju in ohranjanju njenih korenin.

Mobilizacijske sposobnosti glasbe so izrabljali vsi režimi. ${ }^{10}$ Njihovi nasprotniki so uporabljali isto orožje in bili pri tem pogosto uspešnejši. Umetniška vrednost glasbe je pogosto lahko tudi vprašljiva. Zato je treba izhajati iz analize doseganja zastavljenih ciljev in šele potem iskati umetniške vrednosti in vsebine. Kljub temu pa je ne gre podcenjevati, saj je vrsta zborovskih pesmi iz tistih obdobij še vedno standardni del koncerov številnih pevskih zborov. Prav tako so tudi sestavni del ikonografije državnih proslav. Glasba je bila zlasti pomembna v usodnih časih, saj na čustva veliko bolj vpliva kot govorjena beseda. Vsekakor je dejstvo, da sta njena vloga in pomen pri zgodovinskih raziskavah preveč podcenjena.

\section{MUSIC AND NATIONAL CONSCIOUSNESS}

\section{Summary}

Until the establishment of Mohorjeva družba (St Hermagoras Publishing House) in 1851 the Slovenes had no common institution, whether secular or ecclesiastical. They identified themselves primarily through the use of the Slovenian language. At least from 1810 onwards, they referred to the area that they inhabited as "Slovenija".

Slovenian historiography emphasizes the Slovenian language as the most fundamental element of national self-determination. However, detailed research into the Slovenian national movement demonstrates that individuals were most frequently won over to the national cause through singing. One of the most conspicuous examples of such activity is provided by Anton Martin Slomšek, who was initially a "spiritual" (a priest responsible for the spiritual nurturing of his pupils) in the theological seminary at Celovec/Klagenfurt, later a curate and parish priest, and finally Lavantine Bishop, with his see at Šentandraž (Sankt Andrä). Slomšek's approach was shared by other protagonists of the national movement, especially those who advocated the concept of 'cultural betterment from below', that is, from the broadest masses upwards.

Slovenian singing also became an important element of the national movement in the revolution of 1848-49. Its permanent monument is the musical collection Slovenska Gerlica (The Slovene Turtledove). One of the ways in which the movement operated was via choirs; the most renowned of these was that of the "Slovenija" Society in Graz, which numbered among its members the famed Ipavec brothers.

Music was of extreme importance also for the "čitalnice" movement. "Čitalnice" can be translated roughly as "reading societies", while the "čitalnice" movement refers to cultural-political activity in boroughs and towns - a regular activity of these societies was organizing readings of Slovenian or Slav books and newspapers, and sometimes also

${ }^{10} \mathrm{~V}$ tem pogledu so izjemno zanimivi posnetki usposabljanja hrvaške vojske pred akcijo Oluja. 
other cultural events. The artistic level of such events was subordinated to the aims of the national movement and its criteria for national awakening. The primary goal was the use of the Slovenian language in public and the fostering of Slovenian talent. Even though the aesthetic level of these events was subordinated to political aims, several singers who started out at "čitalnice" went on to achieve international success.

The "čitalnice" movement gave birth to the "taborsko" movement. "Tabori" were mass, open-air rallies that took place between 1868 and 1871; each of them attracted between 5,000 and 30,000 people. These rallies gave a platform to those exponents of the national sentiment who enjoyed a reputation as great orators. After the political speeches, the rallies continued with cultural events that included singing and instrumental performance. For this purpose, the organizers hired sections of army bands, while at the same time ensuring that the musical programme was aligned with the aims of the rally. The importance of music was increasing. To raise its level and enhance Slovenian musical creativity, the music society "Glasbena matica" was established in Ljubljana in 1872. Its primary aims lay in education and publishing. The growth and expansion of music life in Slovenia benefited greatly from the contribution of numerous Czech musicians.

With the establishment of political parties after 1890, political competition soon came to manifest itself in the cultural arena, which resulted in the establishment of numerous choirs and musical groups and bands. Tamboura bands (tamboura is a folk string instrument) enjoyed a special reputation as distinctively Slavic. Such music, especially vocal, was cultivated also among Slovenian expatriates in Europe and the USA.

Singing was of extreme importance in the period between the two World Wars. In Yugoslav Slovenia, it represented one form of resistance to Yugoslav centralism, while in Fascist Italy and in Austria it became a principal form of national protest - for which some choirmasters paid with their lives.

The importance of music during the civil war of 1941-45 is shown by the fact that nearly all the musicians who formed the wind band of the anti-communist formation, including their conductor, were liquidated after the war.

After World War II that part of the choral culture that was linked to church singing began to decline. Despite this, it never died out, and it also became a factor in the process of democratization of Slovenian society. Even in the fifteen days of the war for Slovenian independence in 1991 Slovenian soldiers were already beginning to form military vocal ensembles. 